Cad.Est.Ling., Campinas, 48(1):23-31, 2006

\title{
CONSTRUÇÃO/RECONSTRUÇÃO DE OBJETOS-DE-DISCURSO: MANUTENÇÃO TÓPICA E PROGRESSÃO TEXTUAL
}

\author{
INGEDORE G. VILLAÇA KOCH (UNICAMP/CNPq) \\ MARIA ANGÉLICA DE O. PENNA* (UNICAMP)
}

\begin{abstract}
We postulate in this paper that the construction/reconstruction of discourse objects, in accordance to the principles of centration, concernence, relevance and organicity, is of fundamental importance not only for topic maintenance, as for its identification by the reader or the analist. Among the factores that collaborate to the construction of discourse objects, we choose Nominal Referential Forms, which we consider some of the main decisions made by readers/writers in order to accomplish their projects of meaning.
\end{abstract}

\section{INTRODUÇÃ̃O}

Um texto compõe-se de segmentos tópicos, direta ou indiretamente relacionados com o seu tema geral ou tópico discursivo. Um segmento tópico [ST], quando introduzido, mantémse por um determinado tempo, após o qual, com ou sem intervalo de transição (transition span, cf. GOUTSOS, 1996), pode ocorrer introdução de um novo ST.

A progressão tópica pode realizar-se de maneira contínua ou descontínua. A continuidade dá-se, quando, após o esgotamento de um dado ST, mantém-se o tópico em andamento ou ocorre o que se tem denominado topic shift, isto é, um desvio do tópico em curso que não chega a provocar ruptura. A descontinuidade, por sua vez, dá-se em casos de quebra ou ruptura antes que o segmento se esgote. Aos segmentos que provocam descontinuidade tópica, costumase denominar segmentos ruptores ou digressivos.

São as seguintes as propriedades do tópico, tal como descritas em JUBRAN et al. (1992) e JUBRAN (2006):

1. Centração: direcionamento dos diversos enunciados formadores de um tópico para o desenvolvimento de um mesmo tema [aboutness]; envolve as propriedades de concernência e relevância, que nos interessarão neste trabalho:

- Concernência : relação de interdependência semântica entre os enunciados - implicativa, associativa, exemplificativa ou de qualquer outra ordem - pela qual se dá sua inserção num conjunto de referentes explícitos ou inferíveis que se encontram ativados em determinado momento do discurso. [grifo nosso]

- Relevância: proeminência desse conjunto de referentes em determinado segmento textual, ou mesmo no texto inteiro, em virtude da posição focal assumida pelos seus elementos.

- Pontualização: localização desse conjunto em determinado momento do texto.

\footnotetext{
* Doutoranda do programa de pós-graduação em Lingüística da Universidade Estadual de Campinas
} 
KOCH \& PENNA - Construção/reconstrução de objetos-de-discurso...

2. Organicidade: manifestada por relações de interdependência tópica que se estabelecem simultaneamente no plano linear e no plano hierárquico.

Portanto, um dos requisitos para que um texto seja considerado coerente, é que apresente continuidade tópica; ou seja, é necessário que a progressão tópica se realize de forma que não ocorram rupturas definitivas ou interrupções excessivamente longas do tópico discursivo em andamento: inserções e digressões desse tipo necessitam de alguma espécie de justificativa para que a construção do sentido - e, portanto, da coerência - não venha a ser prejudicada. Em outras palavras: a topicalidade constitui um princípio organizador do discurso.

\section{DESENVOLVIMENTO TÓPICO}

É comum, ao abrirmos uma obra, depararmo-nos com um índice que a divide em capítulos, que se subdividem em itens $[1.1 ; 1.2$ etc.], assim como também se costuma esperar que cada item seja tratado de maneira a "esgotar-se" para que se possa prosseguir a leitura sem prejuízo do sentido geral da obra. É comum que, também na fala, o processo se realize de maneira semelhante: por ser localmente planejada, podemos dizer que estamos sempre atentos à apreciação que nosso ouvinte possa fazer do que está sendo dito e, por isso, somos levados a introduzir correções, especificações, explicações. Enfim, procuramos enquadrar nosso coenunciador na mesma moldura comunicativa a que pertencemos, a fim de que o menor número de conteúdos seja perdido. E, quando falamos, procuramos acrescentar algum tipo de informação adicional ao universo discursivo de nosso ouvinte/leitor.

Isso significa que tentamos "segurar as rédeas" de nossa fala ao mesmo tempo em que, mais que esclarecer, procuramos convencer nosso co-enunciador da relevância do assunto em questão. Disso se conclui que os discursos, ainda que comportem uma série de segmentos digressivos, são organizados, de modo que, ao final de uma leitura ou uma conversação, seja possível ao leitor/ouvinte abstrair o conteúdo global; ou melhor, de maneira geral, os temas de nossos textos tendem a ser únicos ${ }^{1}-$ o que nos permite, por exemplo, ao terminar de ler uma obra, por mais densa que seja, reproduzir, em poucas palavras, sua essência.

O caráter interativo da atividade discursiva torna-se altamente evidente nesse processo de manutenção tópica. Para que o falante/escrevente consiga concretizar seu projeto de dizer faz-se necessária a colaboração do ouvinte/leitor; isto é, faz-se necessária a sua inserção no mesmo contexto sócio-cognitivo do produtor; o partilhar de conhecimentos entre ambos; o esforço cognitivo do co-enunciador no sentido de produzir inferências; enfim, a disposição para "negociar" o sentido.

Do lado do produtor do texto, essa colaboração se dá, sobretudo, na projeção que faz do ouvinte/leitor - o que justificaria o elevado índice de explicações; retificações; repetições, em virtude de momentos em que o falante julgue, de alguma forma, problemáticas as suas colocações, dado o caráter constitutivamente instável da linguagem (AUTHIER-REVUZ,1998)

Assim, conhecimentos partilhados pelos co-enunciadores são de grande importância para a construção dos sentidos de um texto, pois são responsáveis por uma série de associações que

${ }^{1}$ Em Bakhtin [Volochinov], (1929/2004, cap. 7,p.128), encontra-se a seguinte tese: "um sentido definido e único, uma significação unitária,é uma propriedade que pertence a cada enunciação como um todo. Vamos chamar o sentido da enunciação completa o seu tema .O tema deve ser único. Caso contrário não teríamos nenhuma base para definir a enunciação." (grifos do autor) 
Cadernos de Estudos Lingüísticos 48(1) - Jan./Jun. 2006

determinarão, não apenas o fio discursivo, mas também a orientação argumentativa. Desse modo, um tema mantém-se, principalmente, graças a processos de sinonímia, hiperonímia, hiponímia, meronímia, pronominalizações, repetições, rotulações, nominalizações - que atuam como reativadores [ou "rememorizadores"] de um tópico introduzido. São justamente esses processos que constituem a atividade de referenciação.

Em KOCH (2004, p.62), lemos que

Na constituição da memória discursiva, estão envolvidas, como operações básicas, as seguintes estratégias de referenciação:

1. Construção/Ativação: pela qual um "objeto" textual, até então não mencionado, é introduzido, passando a preencher um nódulo ("endereço" cognitivo, locação) na rede conceitual do modelo de mundo textual: a expressão lingüística que o representa é posta em foco na memória de trabalho, de tal forma que esse "objeto" fica saliente no modelo.

2. Reconstrução/ reativação: um nódulo já presente na memória discursiva é reintroduzido na memória operacional, por meio de uma forma referencial, de modo que o objeto-de-discurso permanece saliente (o nódulo continua em foco).

3. Desfocalização/desativação: ocorre quando um novo objeto-de-discurso é introduzido, passando a ocupar a posição focal. O objeto retirado de foco, contudo, permanece em estado de ativação parcial (stand by), podendo voltar à posição focal a qualquer momento; ou seja, ele continua disponível para utilização imediata na memória dos interlocutores.[...]

A reconstrução/reativação de "objetos” textuais parece ser, em grande parte, a responsável pela progressão textual. A manutenção tópica se dá, em um elevado número de casos, graças às formas nominais referenciais, pois são elas que melhor representam as escolhas a que os indivíduos procedem por ocasião da construção de objetos-de-discurso (MONDADA \& DUBOIS, 1995), a partir de conhecimentos pressupostos como partilhados e, portanto, da focalização de traços do referente que o locutor julgue de maior relevância para a caracterização do objeto que pretende construir - o que implica uma certa manipulação do referente de acordo com suas crenças, atitudes e opiniões. Por esta razão, a atividade de referenciação encontra , neste trabalho, espaço privilegiado, pois se pretende demonstrar que um tópico discursivo mantém-se em estado de ativação, em grande parte, por meio de processos referenciais.

\section{AS FORMAS NOMINAIS REFERENCIAIS E A PROGRESSÃO TÓPICA}

As Formas Nominais Referenciais, por serem lídimas representantes das escolhas a que os usuários procedem para a realização de seus projetos de dizer, revelam-se importantes meios estratégicos de operar com os objetos-de-discurso, orientando argumentativamente a construção conjunta destes. Por resultarem de escolhas de um locutor que constrói sua fala/escrita em interação com seu interlocutor, elas, muitas vezes, deixam entrever uma apreciação manipulativa do objeto, por parte do primeiro. São também responsáveis por inserir os co-enunciadores em uma moldura comum, uma vez que ativam conhecimentos partilhados. Além disso, confirmam ou frustram as expectativas que o leitor/ouvinte leva para o texto, dando 'asas' a uma negociação para a construção dos sentidos. 
KOCH \& PENNA - Construção/reconstrução de objetos-de-discurso...

O que procuramos evidenciar, portanto, é que:

- O discurso constrói o objeto a que faz remissão;

- a construção desse objeto se dá de maneira estratégica [porque visa à concretização de um projeto de dizer];

- as estratégias de construção envolvem colaboração mútua [portanto, o objeto-de-discurso é construído interativamente];

- essa colaboração envolve, necessariamente, inserção dos parceiros em dada moldura sóciocognitiva;

- as estratégias usadas para a construção do objeto-do-discurso e, portanto, para a progressão referencial [entre elas, as formas nominais referenciais], são responsáveis pela progressão textual e manutenção do tópico discursivo.

\section{EXEMPLIFICAÇÃ̃O}

Tomaremos como exemplo um artigo de opinião publicado na Folha de São Paulo, no dia 24/03/2005, assinado por Demétrio Magnoli. Podemos verificar, na elaboração do texto, que o autor traça um perfil do que seria para ele [e para a maneira como ele pretende que o leitor a interprete] "A queda" a que se refere o título da matéria.

O texto progride e o tópico vai se mantendo graças à construção/reconstrução progressiva do objeto introduzido, que se dá, em grande parte, por escolhas lexicais que vão dando pistas ao interlocutor sobre a interpretação desejada:

\section{FolHa opinião}

São Paulo, quinta-feira, 24 de março de 2005

\section{DEMÉTRIO MAGNOLI}

\section{A queda}

1. A democracia é o conflito organizado. Nas suas duas formas básicas, o jogo democrático oferece recompensa e riscos à classe política.

2. No sistema parlamentar, o Executivo é uma emanação do Parlamento. A maioria parlamentar nomeia o primeiro-ministro e governa por meio do seu gabinete. $\mathrm{O}$ chefe de governo e seus ministros podem cair por decisão dessa maioria. Em compensação, no caso de impasse, o chefe de Estado antecipa eleições, encerrando o mandato dos parlamentares.

3. No sistema presidencial, o Executivo é independente. O presidente tem mandato fixo, bem como os parlamentares. O presidente governa auxiliado pelos ministros, que nomeia sem interferência do Parlamento. Mas a maioria parlamentar pode bloquear iniciativas do Executivo, impondo ao presidente mudanças de rota política e programática.

4. O sistema político brasileiro degenerou a ponto de se tornar inclassificável. A classe política distorceu o jogo democrático de modo a acumular as recompensas e extirpar os riscos dos dois sistemas. O Executivo usufrui de mandato fixo, mas tem a estranha garantia de que seus projetos 
Cadernos de Estudos Lingüísticos 48(1) - Jan./Jun. 2006

essenciais não serão recusados no Parlamento. A maioria parlamentar nomeia, indiretamente, os ministros, mas não governa e não corre o risco de enfrentar eleições antecipadas. A regra do jogo é parasitar o aparelho de Estado.

5. A transação entre os políticos esvaziou a política de seu sentido público. Um Mercadante sacrifica qualquer programa em troca do cargo de governador paulista; um Calheiros tem como programa servir ao poder de turno, e ser servido por ele; um Severino nem sequer sabe o que é programa (na acepção política) e contenta-se em prover sua clientela com sinecuras públicas(1). O espetáculo deprimente do comércio de ministérios (3) não é propriamente uma novidade, mas a linguagem que o reveste não tem precedentes. Mercadantes, Calheiros e Severinos (1) acreditam que a opinião pública perdeu a capacidade de discernir política de corrupção.

6. Maquiavel ensinou que o príncipe virtuoso ergue instituições sólidas. Tradução: na política, a virtude é pública, não privada, e depende das regras do jogo. A putrefação da democracia brasileira (3) é fruto de regras que premiam os Mercadantes, Calheiros e Severinos (1), selecionando uma classe de parasitas da coisa pública (2).

7. A queda (4) não começou no governo Lula, mas foi acelerada pela dinâmica de um governo fundado no pecado original da renúncia programática. Hoje, o presidente é refém da escória política que adquiriu poder suficiente para exigir sem rodeios o pagamento de resgates provisórios e sucessivos sob a forma de pedaços específicos da máquina do Estado. A recusa presidencial em pagar a parcela vencida do resgate poderia representar uma mudança de rumo, mas provavelmente apenas acrescenta juros ao próximo desembolso.

8. O baile da ilha Fiscal (5) tem efeitos corrosivos que não atingem apenas o governo ou a classe política, mas as próprias bases da democracia. A figura do "condottieri", do tribuno da plebe, move-se nas franjas do sistema político brasileiro à espera de uma nova oportunidade. O discurso da virtude moral, dirigido contra os políticos e o jogo político, foi a base do governo Collor e, em tom menor, da candidatura Ciro Gomes. O governo Lula reativa seu apelo popular, descortinando o caminho para pretendentes ao papel de salvador da pátria.

Veja-se como a escolha das formas nominais referenciais orienta argumentativamente e possibilita a construção conjunta do objeto-do-discurso nos parágrafos $5 ; 6 ; 7$ e 8 :

(1) A transação entre os políticos esvaziou a política de seu sentido público. Um Mercadante sacrifica qualquer programa em troca do cargo de governador paulista; um Calheiros tem como programa servir ao poder de turno, e ser servido por ele; um Severino nem sequer sabe o que é programa (na acepção política) e contenta-se em prover sua clientela com sinecuras públicas.

[...] Mercadantes, Calheiros e Severinos acreditam que a opinião pública perdeu a capacidade de discernir política de corrupção.

Pode-se observar a dependência associativa entre as formas um Mercadante; um Calheiros e um Severino com relação ao enunciado anterior [A transação entre os políticos esvaziou a política de seu sentido público]; no entanto, tais formas são introduzidas no discurso como se fossem novas, sugerindo uma recategorização dos nomes próprios em questão - que de próprios passam a comuns. O que permite essa recategorização parece 
KOCH \& PENNA - Construção/reconstrução de objetos-de-discurso...

ser um dado traço comum aos indivíduos Mercadante, Calheiros, Severino com relação aos papéis que estes representam. ${ }^{2}$

É importante ressaltar que a dependência associativa que se observa entre os nomes Mercadante, Calheiros e Severino, ancorados à expressão os políticos do enunciado anterior, dá-se pelo conhecimento de mundo dos interlocutores. Parece claro que há, aí, uma relação de ingrediência [situada] ${ }^{3}$. No entanto, ao serem introduzidas por indefinido, as expressões $u m$ Mercadante; um Calheiros e um Severino já não mais retomam a expressão os políticos como um todo e sim remetem aos políticos que esvaziaram a política de seu sentido público. Isso nos leva a crer que não há, nesse processo, uma retomada pontual de referentes, mas uma operação de recategorização ou rotulação.

O que nos permite tratar essas formas como referenciais é o fato de podermos recorrer ao cotexto precedente e ao conhecimento de mundo do leitor para classificar seus referentes, em uma primeira instância, como o protótipo de político. Protótipo este, que sofrerá recategorização posterior, mas que, ainda assim, pertencerá à classe política.

Em Mercadantes, Calheiros e Severinos acontece algo semelhante à construção que se dá por $u m+$ nome próprio, com a diferença de que aqui, com âncora na construção anterior, o nome pluralizado é apresentado como conhecido do leitor.

Semelhante estratégia é usada em

A putrefação da democracia brasileira é fruto de regras que premiam os Mercadantes, Calheiros e Severinos

em que se pode comprovar a recategorização operada nos nomes pelo excerto

(2) [...] é fruto de regras que premiam os Mercadantes, Calheiros e Severinos, selecionando uma classe de parasitas da coisa pública.

o que vem confirmar a expectativa primeira do leitor, quando da introdução dos nomes por meio do artigo indefinido.

O que é relevante para o que se defende aqui, no entanto, é o fato de que essa recategorização, ou melhor, a escolha por esse tipo de estratégia, imprime uma avaliação do autor e, em consequiência, há um encaminhamento para aquilo que ele projetou desenhar como a queda.

(3) "O espetáculo deprimente do comércio de ministérios [...]"; "A putrefação da democracia brasileira $[\ldots] "$

${ }^{2}$ Ilari (2005), ao comentar esse tipo de anáfora, diz, entre outras coisas, o seguinte:

“[...] Poderíamos nos perguntar que operações retóricas intervêm nessas retomadas: elas têm certamente algo a ver com a figura da antonomásia, pela qual o anfitrião da peça se torna o símbolo de todas as pessoas que hospedam alguém; elas têm também alguma coisa em comum com o processo de identificação de papéis temáticos, porque partimos de casos singulares e abstraímos deles algumas representações mais gerais [...]"

${ }^{3} \mathrm{Na}$ verdade, para questões de Referenciação, estaremos sempre falando em relações situadas, uma vez que postulamos a instabilidade das categorias lingüísticas. No entanto, a relação que se dá no contexto analisado é bastante provisória, pois trata-se do cenário político brasileiro atual. Poderá haver sempre mercadantes, calheiros e severinos [pessoas que representem tal papel], porém nem sempre esses nomes estarão presentes na memória discursiva do leitor como representantes da classe política nacional. Por isso, postulamos mais à frente que, a nosso ver, trata-se de uma operação de rotulação. 
Cadernos de Estudos Lingüísticos 48(1) - Jan./Jun. 2006

Essas expressões "empacotam" o conteúdo do cotexto precedente, rotulando-o. Têm como característica comum o fato de apresentar o novo com capa de velho. Desse modo, ocorre uma orientação no sentido de levar o leitor a construir, conjuntamente com o produtor [ainda que dele discorde], o que seria, para este último, a queda.

(4) A queda não começou no governo Lula, mas foi acelerada pela dinâmica de um governo fundado no pecado original da renúncia programática.

A forma nominal a queda concretiza a proposta de sentido do produtor. Trata-se de um objeto que vem sendo perfilado desde o começo do texto. Apesar de ser, como no exemplo (3), um SN rotulador e apresentar propriedades semelhantes às das formas do exemplo acima, esse sintagma, diferentemente dos SN rotuladores supracitados, consegue encapsular quase todas as predicações cotextuais - tanto anteriores quanto posteriores. ${ }^{4}$

(5) O baile da ilha Fiscal [...]

Esta expressão, apesar de apresentar-se de forma parecida com as do exemplo (3), ou seja, apesar de empacotar conteúdos do cotexto precedente, funcionando como rótulo, constitui um elemento forte para a comprovação de nossa hipótese de trabalho: além de colaborar para a construção do objeto temático por remissão ao cotexto, apela para o conhecimento de mundo do leitor, dado que remete à queda do Império, quando, em novembro de 1889, no palácio da ilha Fiscal, no Rio de Janeiro, comemoravam-se as bodas de prata da princesa Isabel com o Conde d'Eu, ao mesmo tempo em que, no Clube Militar, Benjamin Constant presidia uma reunião que resultaria em golpe militar. Mais que isso, a expressão o baile da Ilha Fiscal traz à memória o luxo, a pompa com que se cobriam os nobres e o descaso pelas questões que ameaçavam a queda do império [abolição da escravatura, resquícios da guerra do Paraguai, questões religiosas, advento da República nos demais países do continente].

É interessante, portanto, notar a remissão que faz essa expressão [o baile da llha Fiscal] à vulnerabilidade do Império, pois enquanto este estava em seus estertores, os nobres dançavam na Ilha Fiscal.

Observe-se como se dá a progressão referencial e desenvolvimento tópico no texto dado:

1. O título: A queda [introduz o tópico e sinaliza um projeto de dizer]

2. Os três primeiros parágrafos:

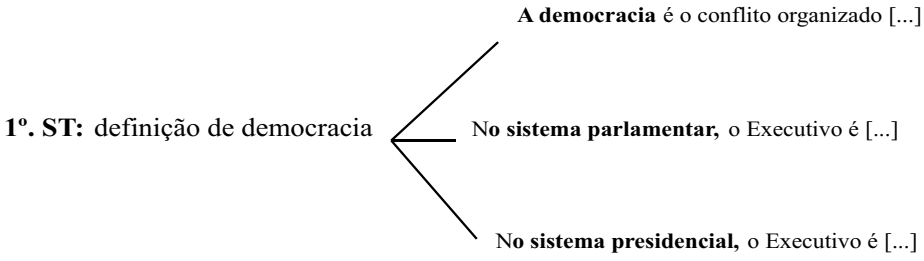

${ }^{4}$ Gill Francis (1994), em seus estudos, faz uma divisão dos rótulos em prospectivos e retrospectivos em que os primeiros seriam preditivos e os segundos avaliativos. O que se observa, no entanto, no texto em questão é que a forma nominal $A$ queda tanto rotula predicações anteriores quanto posteriores à sua realização lexical. 
KOCH \& PENNA - Construção/reconstrução de objetos-de-discurso...

3. Parágrafo 4:

$2^{\circ}$. ST: A degeneneração do sistema político brasileiro [o começo da queda]

Aciona as expectativas do leitor quanto à queda moral da democracia brasileira.

\section{Parágrafos 5; 6 e 7:}

\section{$3^{0}$. ST: manifestações evidentes da queda:}

orientação argumentativa que se efetiva por meio de estratégias referenciais, sendo que o parágrafo 7 retoma o título a queda, já agora como objeto dado para o leitor

\section{Parágrafo 8:}

\section{$4^{\circ}$. ST: O baile da Ilha Fiscal:}

já não remete mais à queda moral da democracia e sim ao fim do governo imperial, à queda do imperador por um golpe militar.

Este parágrafo, então, introduz uma ruptura no conceito de queda. Essa ruptura re-orienta o olhar do leitor para a possibilidade de uma nova construção de sentido para o objeto queda. Há aqui uma possibilidade de ler queda como iminência de golpe, em decorrência da vulnerabilidade em que se encontra o sistema.

O objeto "A queda" manteve-se em estado ativo no decorrer do fio discursivo e muito da manutenção desse estado deveu-se às escolhas por formas nominais que cumprissem o objetivo de construí-lo de modo conforme ao objetivo visado, contando, para tanto, com o enquadramento sócio-cognitivo dos co-enunciadores.

\section{CONSIDERAÇÕES FINAIS}

Dissemos, no início deste trabalho, que objetivávamos evidenciar como a construção/ reconstrução de objetos-de-discurso é fundamental para a manutenção do tópico discursivo e para a identificação deste por parte do leitor. As propriedades de centração, concernência e relevância, apontadas como as que, particularmente, nos interessavam para a demonstração de nossa tese, são as responsáveis por tornarem visíveis e analisáveis as operações que se dão na elaboração conjunta de um projeto de dizer.

Diversos fatores colaboram para a construção de objetos-de-discurso; optamos, no entanto, pelas Formas Nominais Referenciais, por julgarmos serem estas as melhores representantes das escolhas dos usuários visando à concretização de seus objetivos comunicativos. Esperamos que nossa análise tenha sido esclarecedora no sentido de demonstrar que a construção de objetosdiscurso é estratégica e que dela dependem, em grande parte, a manutenção tópica e a progressão textual.

\section{REFERÊNCIAS BIBLIOGRÁFICAS}

AUTHIER-REVUZ, J. (1998). Palavras incertas. As não-coincidências do dizer. Campinas,São Paulo: editora da UNICAMP. 
Cadernos de Estudos Lingüísticos 48(1) - Jan./Jun. 2006

BAKHTIN (Voloshinov). (1929-1930). Tema e significação na língua. In: Marxismo e filosofia da linguagem, pp. 128 -136. São Paulo: Hucitec, 1992.

CONTE, M. E. (1996). Encapsulamento anafórico. In Cavalcanti,M.M; Rodrigues, B. B; Ciulla, A.L (2003) Referenciação. São Paulo:Contexto.

FRANCIS, G (1996). Rotulação do discurso: um aspecto da coesão lexical de grupos nominais. In Cavalcanti,M.M; Rodrigues, B. B; Ciulla, A.L (2003) Referenciação. São Paulo:Contexto

JUBRAN, C. C. A. S. et al. (1992). Organização tópica da conversação. In: ILARI, R. (Org.). Gramática do Português Falado. Campinas: UNICAMP; São Paulo: FAPESP,. V.2, pp. 341- 428.

JUBRAN, C. C. A. S. (2006). Tópico discursivo. In: JUBRAN, C.C.A.S. \& KOCH, I.G.V. (Orgs.). Gramática do Português Culto Falado no Brasil. Campinas: Edunicamp, pp.89-132.

KOCH, I. G.V.(2001). A referenciação como atividade cognitiva e interacional /Conferência apresentada no II Congresso Internacional da ABRALIN. Fortaleza. . (2004). Introdução à Lingüística Textual. São Paulo: Martins Fontes.

. (2004). Sobre a seleção do núcleo das formas nominais anafóricas na progressão referencial. In: Sentido e significação - em torno da obra de Rodolfo Ilari, pp. 244 - 262 .São Paulo: Contexto.

KOCH, I.G.V \& MARCUSCHI, L.A.(1998). Processos de referenciação na produção discursiva. Delta, 14: pp.169-190

MONDADA, L. (2003). La constrution de la réferénce comme travail interactif: accomplir la visibilité du détail anatomique durant une opération chirurgicale. In: Cadernos de Estudos Lingüísticos, 44: pp. 57-70. Campinas, São Paulo.

MONDADA, L. \& DUBOIS. (1995). Construção dos objetos de discurso e categorização: Uma abordagem dos processos de referenciação. Clássicos da Lingüística I, in Cavalcanti, M.M; Rodrigues, B. B; Ciulla, A.L (2003) Referenciação. São Paulo:Contexto

PENNA, M.A.O.(2006). As Formas Nominais Referenciais e suas funções na progressão textual. UNICAMP IEL : dissertação de mestrado. 